\title{
The Mental Lexicon and English Vocabulary Teaching
}

\author{
Huaqing $\mathrm{He}^{1} \&$ Yunfei Deng ${ }^{1}$ \\ ${ }^{1}$ School of Foreign Languages, China West Normal University, Nanchong, China \\ Correspondence: Huaqing He, School of Foreign Languages, China West Normal University, No. 1 Shi Da Road, \\ Nanchong, 637009, Sichuan, China. Tel: 86-817-231-1856. E-mail: masha4567@sina.com
}

Received: March 19, 2015 Accepted: May 7, 2015 Online Published: June 29, 2015

doi:10.5539/elt.v8n7p40 URL: http://dx.doi.org/10.5539/elt.v8n7p40

\begin{abstract}
In China, English as a foreign language (EFL) learning mainly occurs in the classroom, and the resultant lack of practice using English in authentic settings makes it quite difficult for many Chinese learners to learn English words. They may often feel that English words are "difficult to learn and easy to forget." As such, how to effectively teach English vocabulary in classrooms is an essential point for English teachers. Assuming that the goal of vocabulary teaching is to build up students' mental lexicon, this paper first briefly introduces the properties of the mental lexicon and examines differences between the mental lexicon and (print or electronic) dictionaries. More importantly, it then discusses how to teach English vocabulary based on a proper understanding of the organization of the mental lexicon and means of accessing it. Finally, the author poses some suggestions on vocabulary teaching: learning words from context as against word lists, establishing semantic relations between words, providing learners with frequent exposure to words, and teaching morphological knowledge pertaining to the words.
\end{abstract}

Keywords: mental lexicon, lexical access, word memorization, English vocabulary teaching

\section{Introduction}

Vocabulary is a crucial component of language, an idea eloquently expressed by Wilkins (1972, p. 111) who stated that "while without grammar little can be conveyed, without words nothing can be conveyed." The Chinese language is composed of ideographic characters rather than speech-sound-based spellings, and partly for this reason is markedly different from English in terms of word-formation and other aspects (Xiao, 2002). Thus, learning English vocabulary is a tedious task for most Chinese learners, who must master an unfamiliar alphabet and phonetic system in addition to new lexical and morphosyntactic notions such as articles, phrasal verbs, and case endings. These individuals may often feel that English words are "difficult to learn and easy to forget".

Liu $\mathrm{Na}$ and Nation (1985) determined that learners must acquire a vocabulary size of at least 3,000 words to efficiently learn from context while reading an unsimplified text. This is a substantial number of words, representing a substantial time and cognitive investment, to acquire a start-up vocabulary that merely allows a learner to comprehend general texts. According to the College Teaching Syllabus for English Majors in China (2000), graduates should be able to recognize around 10,000 to 12,000 words in English and use 5,000 to 6,000 of them actively and skillfully. In comparison, the College Teaching Syllabus for Non-English-Majors (1999) maintains only that a student, finishing two-year English learning in college should be capable of recognizing between 4,200 and 6,500 words. Nevertheless, He (2008) discovered that second-year non-English-majors could only recognize approximately 1,966 out of 3,000 high-frequency words despite seven years of English instruction. Additionally, lexical errors comprise $30 \%$ of all written mistakes made by Chinese college students in English (He, 2009, 2012). Given these deficiencies, how can teachers ensure that their students acquire a substantial vocabulary in the first two years in college, which is the period of time in which college students are required to learn English. This paper discusses how most effectively to teach and learn English vocabulary, based on an up-to-date understanding of the mental lexicon and its processes.

\section{The Notion of a Mental Lexicon}

\subsection{Defining the Mental Lexicon}

The field of psycholinguistics concerns the mental processes involved in language use, such as language acquisition, perception, comprehension, and production. The study of the mental lexicon (or the internal lexicon) is a subfield of psycholinguistics that focuses on the organization of word knowledge in one's permanent 
memory (Carroll, 2000). Gui (2000) expands on Carroll's characterization of the mental lexicon by noting that it encompasses not only how words are stored in one's memory but also how they are retrieved during the act of speaking or writing.

\subsection{Differences between the Mental Lexicon and Standard Dictionaries}

Although the mental lexicon is an abstract concept, it is comparable in obvious ways to a traditional dictionary. However, according to Gui (2000), there are four notable differences between the mental lexicon and a traditional dictionary. First, unlike a standard dictionary, the mental lexicon is not organized in alphabetical order. Second, a dictionary contains a finite number of words and often cannot keep pace with the perpetual evolution of a language; in contrast, the mental lexicon can continuously adapt to the appearance or disappearance of words as well as to changes in their meanings and pronunciations. Third, words in dictionaries are listed in isolation, whereas words in the mental lexicon are grouped according to various properties and relationships. Finally, and most importantly, the mental lexicon includes substantially more information than a dictionary. When one locates a given word in one's lexicon, the properties associated with the word, such as its definition, spelling, and pronunciation, as well as its relationships to other words, is made available. Therefore, when compared to a physical dictionary the mental lexicon is more dynamic and complex.

\section{Organization of and Access to the Mental Lexicon}

Distinct from the organization of the mental lexicon, or how the internal lexicon is structured, is lexical access, which involves activating lexical items from the mental lexicon These two elements are interdependent, since ease of retrieval of information is dependent on how humans store it.

\subsection{Organization of the Mental Lexicon}

Most contemporary scholars maintain that the mental lexicon is a network of interconnected elements, which are concepts or nodes connected to one another by virtue of being semantically related. In this configuration, word meanings are based on their relationship to other words in a network of links.

\subsubsection{The Hierarchical Network Model}

Collins and Quillian's $(1969,1970)$ hierarchical network model is among the most influential semantic network models dealing with word-meaning relationships. The model hypothesizes that words are stored in one's memory in networks, wherein each word or concept represents a node and the relationships between nodes constitute a hierarchy. Some nodes may coexist at the same level as other nodes and be dominated by superordinate nodes; such nodes can also function as superordinate nodes for other subordinate nodes. Every word is connected according to its semantic features in this hierarchical network; an example of such a superordinate-subordinate semantic relationship would be animal-bird-robin. Collins and Quillian $(1969,1970)$ maintain that since the space available for storage of semantic information is limited, it is beneficial to store information in only one network location. This is referred to as the principle of cognitive economy. However, this model is limited, since hierarchies are not necessarily ordered clearly; for example, it is not necessarily clear how to order virtue and goodness.

\subsubsection{Spreading Activation Models}

The spreading activation model (Collins \& Loftus, 1975) also assumes that a network of word relationships exists in the mental lexicon. However, in this model, these relationships are not necessarily organized in a hierarchical fashion; instead, the organization is closer to a web of interconnecting nodes, with the distance between the nodes determined by both structural characteristics such as taxonomic relations and considerations such as typicality and degree of association between related concepts; meanwhile, the retrieval of information is not a structural process but one that involves the "spread" of lexical activation.

Although this original spreading activation model improves upon the hierarchical network model, it is nonetheless still flawed because it does not adequately consider the phonological, syntactic, or morphological aspects of words. In that respect, a more recent version of the spreading activation model presented by Bock and Levelt (1994) is more reasonable, since it presupposes the existence of word knowledge at three levels: conceptual, lemma, and lexeme. Distinguishing between these levels is an important factor in understanding the role of lexical access in comprehension and production. Moreover, it is implicit in Bock and Levelt's model that information in each of the aforementioned levels is stored in an isolated manner, (thus, incidentally, explaining the tip-of-the-tongue phenomenon, that is, when a person knows a word but is temporarily unable to retrieve it) (Carroll, 2000). In terms of the Bock and Levelt model, the speaker knew the word's meaning (the concept) and syntactic category (the lemma), but not its phonological features (the lexeme), at least not in their entirety, The robustness of the spreading activation models, indicated here, has contributed to their popularity in cognitive 
psychology and psycholinguistics.

\subsubsection{Prototype Model}

The prototype model (Putnam, 1975; Lakoff, 1987; Rosch, 1975) does not assume that word meaning is based on a cluster of features but instead that concepts are stored in the form of "prototypes," that is, representations of the most typical members of given conceptual categories. For example, every member of the bird family possesses a quality of "bird-ness", which encompasses a series of features depicting the prototypical bird (e.g., a beak, feathers, two legs, wings, oviparity). However, birds such as swallows, robins, larks, sparrows, and canaries more closely resemble the prototypical bird than do chickens and turkeys, while birds such as penguins do not resemble the prototype very much at all. The major implication of this for vocabulary learning is that concepts in a class constitute a continuum (from the most typical members to the most untypical members), and humans are better at learning typical words first and untypical words later.

Every model has its advantages and disadvantages and cannot capture all of lexicon knowledge. Comparatively speaking, spreading activation model is superior, because it offers the most realistic picture currently available of the internal lexicon (Carroll, 2000).

\subsection{Access to the Mental Lexicon (Lexical Access)}

\subsubsection{Definition of Lexical Access}

Lexical access is the process by which meanings are activated in the internal lexicon. This can happen in several different ways. One way is through the sensory perception of the occurrence of a word. For example, if one sees the word elephant on a printed page, one has the opportunity to identify it as a familiar word and thus to retrieve appropriate knowledge concerning it to assist one in the comprehension process (Carroll, 2000).

\subsubsection{Lexical Access Models}

\subsubsection{The Autonomous Search Model}

The autonomous search model (Forster, 1976, 1979) is one of the most influential lexical access models. The model's word recognition system is divided into two components. Among them, one is devoted to the orthographic properties of words, while another focuses on their phonetic properties. Since these properties involve processing words in terms of the relevant features (that is, one accesses common words more quickly than similar rare words), the model is equipped to account for word frequency effects. However, despite recent revisions, the autonomous search model cannot account for priming and context effects (Carroll, 2000).

\subsubsection{The Logogen Model}

John Morton proposed the logogen model (1969). In this model, words (or morphemes) in a lexicon are represented by "logogens," which are units that indicate a word's various semantic, orthographic, and phonological attributes. A logogen can be activated through either sensory input or contextual information, and these two means are assumed to work in parallel. Although this model is not all-encompassing, it does account for word frequency, priming, and context effects (Carroll, 2000).

\subsubsection{The Cohort Model}

The cohort model (Marslen-Wilson, 1987) was designed to account for auditory word recognition, which it divides into three stages. First, based on an acoustic-phonetic analysis of the input, a set of lexical candidates are activated; these are known as the "word-initial cohort." Next, a member of the cohort is selected for further analysis. Finally, the selected lexical item is integrated into the ongoing semantic and syntactic context. This model in many ways adopts the best features of the search and logogen models. For example, it assumes (like the logogen model) that multiple word candidates are processed in parallel, and (as in the search model) that the initial process is strictly bottom up (Carroll, 2000).

Each model can describe some of the findings, but the cohort model is best positioned to explain the entire array of results (Carroll, 2000).

\subsection{Variables That Influence Lexical Access}

Lexical access is influenced by a variety of factors, including the frequency of a word, its phonological/morphological structure, its syntactic category, the presence of semantically related words, and the existence of alternate meanings of the word (Carroll, 2000). Common words and meanings seem to be in a state of greater readiness than less often used words and meanings. Humans rely on morphological structure when encountering unfamiliar words (Carroll, 2000). 


\section{Implications for English Vocabulary Teaching}

According to Carroll (2000), word knowledge encompasses phonological, syntactic, morphological, and semantic knowledge. Furthermore, Schmitt and McCarthy (2002), on the basis of an examination of the findings of other linguists, identified six details that one must know about a word in order to use and understand it: 1) the word's spoken and written form, including its spelling and pronunciation; 2) its structure (root morpheme, common derivations, inflections, etc.); 3) its syntactic patterns in phrases and sentences; 4) its referential, affective, and pragmatic meanings; 5) its lexical relationships (synonymy, antonymy, hyponymy); and 6) its common collocations.

\subsection{Learning Words from Context versus Word Lists}

Learning words from context is a type of indirect or incidental learning, while learning words from lists is a form of explicit learning. As a result of context effects and semantic priming, contextualized words are recognized more quickly than isolated words; thus, proper context can hasten the recognition of words and eliminate ambiguity. The notion that vocabulary should be taught in context is also supported by the depth (or "levels") of processing hypothesis, which asserts that the more cognitive energy is expended in manipulating and thinking about a word, the more likely it is that the individual will be able to recall and use it (Schmitt \& McCarthy, 2002). Thus, if appropriate contextual clues are supplied, words can leave a deeper imprint in the learner's memory and subsequently have a greater chance of being activated.

Explicit teaching can serve as an excellent introduction to a word, and encountering its context later on through reading can provide one with new knowledge concerning its collocations and additional meanings. Moreover, repeated exposure to a word through reading will aid the learner in consolidating the meanings that he or she has initially learned. Indeed, explicit teaching is essential to learning the most frequently used words in any foreign language, and these words are prerequisites for language use. As such, learning them cannot be left to chance, and they should be taught with immediacy to facilitate further learning. In contrast, less frequently used words are better learned through extensive reading, especially since time constraints generally do not permit one to learn them through conscious study. In short, given that both methods have unique benefits, an approach that utilizes them concurrently should elicit optimum results (Schmitt \& McCarthy, 2002).

\subsection{Establishing Semantic Relations between Words}

In the hierarchical network model, words are represented as nodes connected to other nodes through semantic relationships. Accordingly, teachers should be mindful of these sense relations in order to encourage students to cultivate their own semantic mental networks, which in turn should allow quick access to and retrieval of words.

Gairns and Redman (1986) identified several types of semantic relations that should be taken into taken into consideration when teaching vocabulary. The first concern the various boundaries between conceptual meanings, which entail not only knowing what a word refers to but also how it differs from words that are related in meaning. The second concerns polysemy and homonymy. Polysemy involves distinguishing between the meanings of a single word form with several very closely related meanings (e.g., foot in two sentences He hurt his foot and He stood at the foot of the stairs. The foot is the lowest part of the stairs just as the foot is the lowest part of the human body. In contrast, homonymy requires one to distinguish between the meanings of a word form with several meanings that are generally unrelated (e.g., lie in two sentences you have to lie down and don't lie, tell the truth. Homophony is a third factor that should be considered; it involves understanding word forms that have different spellings and/or meanings yet are pronounced identically. Finally, synonymy, which involves distinguishing subtle differences in meaning between words that ostensibly mean the "same thing," must also be taken in account when teaching vocabulary.

A common approach to illustrating lexical semantic relations between vocabulary words involves dividing these relations into three types: category membership, word associations, and conceptual structures; these are then further divided into superordinate, basic, and sub-basic levels (Cruse, 2000). Words at the basic level are among the most frequently used words, and learning them presupposes the learning of their superordinates; likewise, learning sub-basic level words or phrases presupposes the learning of basic-level words. Words belonging to the same category should be learned together, not only due to their closeness in meaning but also because they frequently co-occur in the same context (e.g., again, animal-bird-robin). Furthermore, words learned within their conceptual structures are better understood and retained than words learned in isolation or alongside/through L1 translations. Assuming that words in the same category are stored in the mental lexicon together, the activation of one word should help activate the others, creating a backdrop conducive to language production. 


\subsection{Providing Learners with Frequent Exposure}

According to the concept of the word frequency effect, frequently used words are recognized more quickly than infrequently used words, and a positive correlation exists between the number of words one is exposed to and the speed and ease with which they are recognized. Vocabulary acquisition is a cumulative activity, not merely an all-or-nothing affair; as such, if a word is encountered frequently enough, it will develop a rich set of connections to other words (Schmitt \& McCarthy, 2002).

Numerous studies have demonstrated that L2 learners can acquire a substantial amount of vocabulary through extensive reading. While frequently exposing oneself to context in this way or other ways (for example, by conversing with native speakers, by watching English films) is one way to increase vocabulary, the repetition of word lists is another. Studies on memory (Schmitt \& McCarthy, 2002) indicate that if a new word is repeated at regular intervals, learners are better able to remember it permanently. This implies that it is preferable to teach vocabulary in separate sessions that are spaced apart rather than in a condensed program. For instance, rather than devote an entire class to vocabulary learning, an instructor might introduce new words at the beginning of a lesson, review them later in the same lesson, and then go over them once again during a new lesson. Although this requires the teacher to plan his or her lessons carefully, such efforts should produce fruitful results.

\subsection{Teaching Morphological Knowledge}

Many psychologists claim that affixational and word root information is organized separately in the mental lexicon, an approach that achieves some storage economy since it does not require one to store all the various forms of a word but merely its root and the set of morphemes used across words of a given class throughout the language. For instance, if you know the morphemes bed, room, and -s, you will quickly be able to produce beds, rooms, bedroom, and bedrooms without necessarily learning each of those words individually. Lexical decision experiments (Carroll, 2000) have shown that response times are greater for affixed words (e.g., unkind) than for non-affixed words (e.g., kind), and shorter for prefixed words (e.g., remind) when compared to words with pseudoprefixes (e.g., relish). Moreover, some studies indicate that while frequently encountered words (e.g., impossible) are represented as single lexical items in the memory, less common words (e.g., imperceptible) are stored as bases plus affixes.

The English vocabulary is conventionally said to contain over one million words; even so, most of them are constituted in an orderly and systematic manner. A learner's ability to decompose a word into its constituent morphemes can facilitate his or her recognition and subsequent production of it. For example, familiarity with the suffix -ship and the word relation should enable a learner to determine the meaning of the word relationship even if he or she has never encountered it before. Indeed, many studies have demonstrated that students learn and retrieve vocabulary more quickly, easily, accurately, and efficiently when the morphological method is integrated into language teaching (Xiao, 2002; Xiao \& Lu, 2005).

\section{Conclusion}

This paper discussed the teaching of vocabulary based on a proper understanding of the mental lexicon or internal lexicon and its processes. The organization of the internal lexicon, as well as variables influencing lexical access, suggests that word lists alone cannot in general lead to the effective learning of words, or allow them to be easily retrieved from the mental lexicon. Moreover, introducing new words in contexts can provide learners with knowledge concerning the collocations and additional meanings of those words, not only their meanings in isolation. Teachers should be mindful of sense relations in order to encourage students to cultivate their own mental semantic networks, which in turn should facilitate quick access to and retrieval of words. The memorization of lexical items in the context of other words has been shown to be effective (Schmitt \& McCarthy, 2002); thus, teachers should expose learners repeatedly and frequently to new words in order to consolidate their vocabulary knowledge for those words. Integrating the morphological method into vocabulary teaching can also help students learn and retrieve words more quickly, easily, and accurately.

\section{Acknowledgement}

This research is financed by the Department of Education of Sichuan Province, China (Project No. 13SA0015).

\section{References}

Bock, K., \& Levelt, W. (1994). Language Production: Grammatical Encoding. In M. A. Gernsbacher (Ed.), Handbook of Psycholinguistics (pp. 945-984). San Diego: Academic Press.

Carroll, D. W. (2000). Psychology of Language (3rd ed.). Beijing: Foreign Language Teaching and Research Press. 
Chinese Ministry of Education. (1999). College Teaching Syllabus for Non-English-Majors (Interim). Beijing: Higher Education Press.

Chinese Ministry of Education. (2000). College Teaching Syllabus for English Majors. Beijing: Foreign Language Teaching and Research Press.

Collins, A. M., \& Loftus, E. F. (1975). A spreading-activation theory of semantic processing. Psychological Review, 82, 407-428.

Collins, A. M., \& Quillian, M. R. (1969). Retrieval times from semantic memory. Journal of Verbal Learning and Verbal Behavior, 8, 240-247.

Collins, A. M., \& Quillian, M. R. (1970). Facilitating retrieval from semantic memory: The effect of repeating part of an inference. Acta Psychology, 33, 304-314.

Cruse, D. A. (2000). Meaning in Language. Oxford: Oxford University Press.

Forster, K. I. (1976). Accessing the mental lexicon. In R. J. Wales, \& E. Walker (Eds.), New Approaches to Language Mechanisms (pp. 257-287). Amsterdam: North-Holland.

Forster, K. I. (1979). Levels of processing and the structure of the language processor. In W. E. Cooper, \& E. C. T. Walker (Eds.), Sentence processing (pp. 27-85). Hillsdale, NJ: Erlbaum.

Gairns, R., \& Redman, S. (1986). Working with words: A guide to teaching and learning vocabulary. Cambridge: Cambridge University Press.

Gui, S.-C. (2000). Psycholinguistics (New Edition). Shanghai: Shanghai Foreign Language Education Press.

He, H.-Q. (2008). Investigation of the acquisition of English high-frequency words by Chinese non-English-major college students. Journal of China West Normal University (Philosophy \& Social Sciences), 2, 43-47.

He, H.-Q. (2009). An analysis of lexical errors in non-English-majors' writing: A corpus-based study. Foreign Language World, 3, 2-9.

He, H.-Q. (2012). A corpus-based study on language errors in non-English-majors' writing. Journal of China West Normal University (Philosophy \& Social Sciences), 3, 97-101.

Lakoff, G. (1987). Women, Fire, and Dangerous Things: What Categories Reveal About the Mind. Chicago: University of Chicago Press.

Levelt, W. (1989). Speaking: From Intention to Articulation. Cambridge, MA: The MIT Press.

Liu, N., \& Nation, I. S. P. (1985). Factors affecting guessing vocabulary in context. RELC Journal, 16(1), 33-42.

Marslen-Wilson, W. (1987). Functional parallelism in spoken word-recognition. Cognition, 25, 71-102.

Morton, J. (1969). Interaction of information in word recognition. Psychological Review, 76, 165-178.

Putnam, H. (1975). The meaning of “meaning”. In H. Putnam (Ed.), Mind, Language, and Reality: Philosophical Papers (Vol. 2). Cambridge: Cambridge University Press.

Rosch, E. (1975). Cognitive representations of semantic categories. Journal of Experimental Psychology: General, 104, 192-233.

Schmitt, N., \& McCarthy, M. (2002). Vocabulary: Description, Acquisition and Pedagogy. Shanghai: Shanghai Foreign Language Education Press.

Wilkins, D. A. (1972). Linguistics in Language Teaching. London: Edward Arnold.

Xiao, H.-S., \& Lu, N. (2005). Towards a scientific teaching of English vocabulary. Sino-US English Teaching, 7, $1-4$.

Xiao, L.-M. (2002). English-Chinese Comparative Studies \& Translation. Shanghai: Shanghai Foreign Language Education Press.

\section{Copyrights}

Copyright for this article is retained by the author(s), with first publication rights granted to the journal.

This is an open-access article distributed under the terms and conditions of the Creative Commons Attribution license (http://creativecommons.org/licenses/by/3.0/). 